\title{
O ESPAÇO DA BRINQUEDOTECA E A PRODUÇ̃̃o DE SENTIDOS ENTRE CRIANÇAS
}

\author{
Luciane Pandini-Simiano \\ Vera Lúcia Chacon Valença ${ }^{(*)}$
}

\begin{abstract}
Cresci brincando no chão entre formigas. De uma infância livre e sem comparamentos. Eu tinha mais comunhão com as coisas do que comparação. Porque se a gente fala a partir da experiência de criança, a gente faz comunhão: de um orvalho e sua aranha, de uma tarde e suas garças, de um pássaro e sua árvore. Então eu trago das minhas raízes crianceiras a visão comungante e oblíqua das coisas.
\end{abstract}

Manoel de Barros, Memórias inventadas

Brincar constitui-se a principal forma da criança ser, estar e se relacionar com mundo. Vozes, gestos, narrativas e cenários são criados, transformados. Uma experiência, marcada pela possibilidade de mudança, renovação, produção de sentidos e significados. ${ }^{1}$

Nas últimas décadas, devido às intensas transformações da vida urbana, limitou-se o convívio informal nas ruas, praças e parques. A grande circulação de automóveis e a falta de segurança nesses locais interferiram, significativamente, nas brincadeiras das crianças e nos espaços do brincar. Esse aspecto demanda reflexões e questionamentos: Do que as crianças brincam hoje? Com quem brincam? Quais os espaços reservados à brincadeira? Diferentes espaços geográficos, educativos e culturais implicam diferentes formas de brincar?

Pesquisas em espaços de educação não-formal, são consideradas como um campo em construção. Tal contexto educativo, é caracterizado pela aprendizagem adquirida "no mundo da vida", via processo de troca de experiências advindas principalmente de espaços e ações coletivas cotidianas. (CERTEAU, 1994). De acordo com GOHN (2006, p. 17), esses espaços por vezes passam por desacreditados, devido ao fato de "as atividades realizadas "fora da escola" ainda serem vistas meramente como recreação ao invés de educação".

No Brasil, em contraposição a esse cenário, recentemente, observam-se alguns estudos referentes à espaços educativos não formais especificamente organizados para o brincar infantil.

\footnotetext{
${ }^{(*)}$ Luciane Pandini-Simiano. Doutora em Educação pela Universidade Federal do Rio Grande do Sul (UFRGS). Professora do quadro permanente do Programa de Pós-Graduação em Educação da Universidade do Sul de Santa Catarina (UNISUL).E-mail: lucianepandini@gmail.com.

Vera Lúcia Chacon Valença. Doutora em Psicologia Aplicada na Université Rene Descartes - Paris V. Professora do quadro permanente do Programa de Pós-Graduação em Educação da UNISUL. E-mail: veravalenca @uol.com.br.

${ }^{1}$ Sentido e significado têm sido tomados como termos diferenciados, mas relacionados. Sentido é concebido como algo pertencente ao universo pessoal do sujeito, mas compartilhado dentro do contexto de interação, já que advém de experiências anteriores, de sua constituição e história; enquanto significado é compreendido como algo culturalmente compartilhado, aceito e concebido socialmente. (JOBIM E SOUZA; PEREIRA (1998), ZANELLA (2004)).
} 
Pesquisas como Kishimoto (1997), Porto (2005), Peters (2009), apontam a brinquedoteca como um espaço educativo não formal privilegiado para o brincar e a ampliação do convívio social da criança. Roucous (1997), atentando para a crescente expansão desses locais, destaca eixos que organizam e caracterizam uma brinquedoteca: espaço físico estruturado para o brincar; acesso à variedade de brinquedos e materiais lúdicos; liberdade de escolha de seus usuários; lugar de encontro para o estabelecimento de relações sociais entre diferentes gerações e culturas. (ROUCOUS, apud PETERS, 2009).

Embora seja possível observar uma multiplicação desses espaços em especial, nos centros urbanos, a brinquedeoteca ainda permanece, invisível, despercebida... Nesse sentido, segundo Kishimoto (2001), é fundamental criar visibilidades para os locais de brincadeiras da infância. Olhares atentos para o espaço, o tempo, o encontro, as relações, os saberes, as significações constituídas e constituintes...

O presente texto aborda tais temáticas ao focar os modos como as crianças ocupam, se relacionam e produzem sentidos e saberes no espaço da brinquedoteca. A partir do diálogo de diferentes autores e perspectivas como Benjamin (2005), Pinto e Sarmento (1997), Santos (2002), Lima (1981), defende-se que, sendo a brinquedoteca um espaço estruturado para o brincar, sua materialidade educa, expressa ideias, comunica mensagens. Porém, essas não são imutáveis. A partir da ocupação e das interações que as crianças estabelecem entre si e com adultos, sentidos e saberes são produzidos e outras significações simbólicas são atribuídas a esses espaços.

Evidenciar as dimensões educativas e produção de saberes e sentidos no espaço da brinquedoteca implica compreender as relações entre a configuração do espaço-físico, seus signos, códigos e conteúdos implícitos; e a representação simbólica dos sujeitos que o habitam, o espaço tomado, vivido, ocupado. Trata-se, portanto, de perceber os sentidos que crianças e adultos atribuem ao espaço quando estão ocupando e se relacionando na brinquedoteca.

Compreendendo as crianças como sujeitos ativos, interativos, competentes, produtores de saberes e não como acessório ou apêndice na sociedade dos adultos, busca-se reconhecer e valorizar a sua capacidade de produção simbólica (PINTO, SARMENTO, 1997, p. 20). Isso requer evidenciar a competência da criança para construir sentidos no e sobre o mundo, não a reconhecendo mais como um "vir a ser", mas como sujeito, alguém que tem desejos, expectativas, alguém que precisa ser valorado. Para tanto, é preciso reconhecer suas formas específicas de ocupar e se apropriar dos espaços, "entendendo a brincadeira como fundamental, tanto para a criança conhecer o mundo quanto para reconhecer-se no mundo.” (BARBOSA, 2004, p. 62). Nessa 
perspectiva, é necessário desenvolver olhares atentos e uma escuta sensível e refinada para as brincadeiras, as relações, as diferentes formas de ocupação e os sentidos estabelecidos...

"Então eu trago das minhas raízes crianceiras a visão comungante e oblíqua das coisas.." Retoma-se a metáfora de Manoel de Barros na epígrafe desse texto. As raízes crianceiras do poeta parecem traduzir a busca de "dar a palavra à infância" ou "vozes às crianças". Deixar as certezas, verdades absolutas de lado e construir estudos que falem das crianças, com crianças e não somente sobre elas. Essa memória convida a entrar na brincadeira, retomar nossas próprias raízes crianceiras e buscar conhecer um pouco mais a respeito das crianças e dos seus espaços de viver a infância.

\section{ELEMENTOS DO PERCURSO INVESTIGATIVO}

Como ponto de partida desta investigação, tem-se as seguintes questões: Quais as configurações fisicas privilegiadas para a organização da brinquedoteca? Como as crianças e adultos ocupam, se relacionam e produzem sentidos e saberes nesse espaço? Que processos educativos são possíveis evidenciar no espaço da brinquedoteca?

Para auxiliar no estudo de tais questões, apresentar-se-ão elementos de uma pesquisa, que contemplou uma brinquedoteca universitária, situada na região sul do estado de Santa Catarina. O enfoque privilegiado é um grupo de 11 crianças com idade entre três e quatro anos e dois adultos, uma brinquedista ${ }^{2}$ e uma estagiária.

A brinquedoteca pesquisada atende a comunidade gratuitamente, oferecendo áreas de brincadeira e um acervo de livros e materiais para consulta. A brinquedoteca dispõe de uma brinquedista que organiza espaços que possibilitam à criança brincar livremente com seus pares; e um grupo de estagiários, professores, e outros profissionais do campo da educação, que estudam e pesquisam questões relacionadas à imaginação e a ludicidade na infância.

A presente investigação caracterizou-se por uma pesquisa de orientação etnográfica (ANDRE, 2000). Os instrumentos foram a observação participante e o diário de campo, enriquecidos pela filmagem. As observações focaram, inicialmente, na configuração do espaço físico da brinquedoteca, tais como: mobiliário, suportes materiais e brinquedos, bem como os aspectos estéticos e funcionais que os envolviam. Posteriormente, as formas de ocupação e relações das crianças entre elas e com adultos no espaço. As observações deram-se no período de seis meses,

\footnotetext{
2 Denomina-se brinquedista o adulto responsável pela organização de contextos que possibilitem o brincar na brinquedoteca. A brinquedista na presente pesquisa é pedagoga.
} 
com periodicidade semanal, tendo em média uma hora de duração por encontro, totalizando 24 encontros.

A análise implicou diferentes exercícios de seleção e categorização das anotações e cenas. Os critérios elencados consideraram: a configuração espacial organizada pelo adulto-brinquedista; a ocupação e os usos que as crianças fazem nas diferentes áreas do espaço da brinquedoteca, em especial ao brincarem; tipos de relações estabelecidas entre crianças e adultos e a produção de sentidos e dos múltiplos significados no espaço.

\section{UM OLHAR PARA O ESPAÇO DA BRINQUEDOTECA}

O espaço, neste trabalho, é entendido como o físico, material, que pode ser pensado, planejado e projetado para certo fim (TUAN, 1983). O espaço é construído na relação com o homem, por isso, não pode ser naturalizado. A infraestrutura não é cindida do tempo e das pessoas, aspecto fundamental a ser investigado, analisado, refletido...

Ao chegarmos à sala da brinquedoteca, deparamo-nos com uma configuração física constituída por chão com piso claro, paredes e tetos brancos. As paredes são de cimento e em uma delas há quatro grandes janelas.

A sala é ampla e colorida. O teto repleto de móbiles que se movimentam ao vento e causam uma boa sensação quando por se está. Tentativas de deixar o espaço aconchegante, tornando-o mais convidativo.

Nas paredes, é possível observar um painel com o nome da brinquedoteca, acompanhado de seus colaboradores e a indicação da data de nascimento de cada um deles. Além desse painel, observam-se, na extensão de todas as paredes, fotografias, diversos desenhos e pinturas feitos pelas várias crianças que frequentam o espaço. Em conversa com a brinquedista, ela evidencia tais produções e fala a respeito: "Olha só que coisa mais linda os desenhos deles! Um é diferente do outro... As crianças ficam felizes quando eu os coloco na parede." (Diário de Campo) Pode-se notar uma valorização das produções das crianças. É oportunizado a elas manifestar e imprimir suas marcas no espaço. As paredes falam, pulsam e revelam o vivido (AGOSTINHO, 2003). As fotografias e desenhos configuram, registram, documentam e imprimem experiências das crianças no espaço.

A organização dos tempos, espaços e objetos são previamente planejados pelo adultobrinquedista. Os contextos material, temporal e relacional buscam potencializar encontros, escolhas individuais e grupais não dependendo constantemente da intervenção direta dos adultos. A 
configuração espacial define oito grandes áreas delimitadas por cantos temáticos: 1) biblioteca; 2) consultório médico; 3) jogos; 4) casa; 5) supermercado; 6) fantasias; 7) plástica, subdividida em desenho, pintura, modelagens; 8) tocas e cabanas. A identidade de cada uma dessas áreas decorre de marcadores físicos repletos de significações implícitas que fornecem, silenciosamente, dados e conteúdos (FERREIRA, 2004), explicitando claramente o que lá se pode ou deverá fazer. Os cantos temáticos expressam "uma espécie de discurso que institui na sua materialidade um sistema de valores que cobrem diferentes símbolos estéticos, culturais e também ideológicos." (VIÑAO FRAGO; ESCOLANO 1998, p. 26). Nesse sentido, sublinha-se a não neutralidade dos objetos nos espaços, o quanto a presença ou ausência de determinados elementos e a forma como são organizados, estão sempre comunicando algo sobre e para as pessoas que ali convivem.

Os elementos que compõe cada uma das oito áreas temáticas são diversos. Os objetos, brinquedos e mobiliário apresentam uma composição física variada, tais como tecidos, plásticos, madeira, papelão, folhas, sementes que ampliam o contato das crianças com diferentes materialidades.

Carvalho e Rubiano (1994) destacam que o arranjo espacial, no que diz respeito à composição de sua materialidade e à maneira como móveis e equipamentos estão dispostos no espaço, podem influenciar na forma de as crianças se relacionarem entre si. No arranjo de cada um dos cantos temáticos da brinquedoteca, existe uma espécie de corredores, que ora limitam, pois circunscrevem e criam espaços relativamente separados entre si, ora potencializam os encontros porque a forma dos seus limites não são fisicamente intransponíveis, permitindo, assim, uma transição rápida e circulação livre entre os espaços. Mesmo na casa, a área mais claramente fechada com "paredes", é possível verificar potencialidades comunicativas entre os sujeitos, já que a pouca altura das aberturas e dos móveis facilita a visão e a escuta entre as crianças que estão no interior com quem está no lado de fora.

A ampla comunicação e mobilidade de circulação pelos cantos temáticos possibilitam às crianças escolhas que favorecem sua autonomia. A materialidade dos objetos que compõe cada uma das oito áreas não são neutras, facilitam a leitura imediata das atividades ali possíveis, podendo condicionar determinadas dinâmicas de brincadeiras. Por exemplo, a casa, composta por fogão, pia, geladeira, louças, avental, sugere em sua materialidade, brincadeiras de cozinhar, dar de comer, etc. Porém, o contexto relacional na brinquedoteca possibilita às crianças o uso criativo e a auto-gestão dos objetos. Assim como também os objetos concretos do consultório médico e do mercado, pelo seu poder expressivo, comunicam, expressam ideias, mas também potencializam múltiplas significações aos usos sociais que as crianças lhe conferem. Ou seja, o espaço da brinquedoteca 
propõe e se compõe fisicamente de itinerários de brincadeiras que comunicam mensagens. As crianças, entretanto, ao se apropriarem desses espaços, criam diferentes enredos, produzem outros sentidos e evidenciam por meio de suas manifestações, a sua capacidade de produção simbólica .

Entende-se o espaço como "um conjunto indissociável de sistemas de objetos e sistemas de ações" (SANTOS, 2002), podemos dizer que são as crianças e adultos que lhe atribuem um conteúdo. O espaço não está pronto, acabado, mas algo que pode ser modificado ao longo da relação que os sujeitos estabelecem com ele.

À medida que as crianças e adultos ocupam o espaço da brinquedoteca, ele ganha novos sentidos e significados. A partir das relações que estabelecem, constrói-se uma configuração que ultrapassa o aspecto material, produzindo outras significações simbólicas.

\section{A PRODUÇÃO DE SENTIDOS ENTRE CRIANÇAS NA BRINQUEDOTECA}

Assim que se chega à brinquedoteca é possível observar nas crianças uma explosão de alegria e curiosidade. Impelidas pelo seu poder de imaginar, fantasiar, criar, significar (KRAMER, 2000), elas adentram o espaço rapidamente, sozinhas ou acompanhadas de seus pares. Na ocupação, nas relações, nas brincadeiras que estabelecem, "influenciam as circunstâncias sociais de existência, são por elas influenciadas e criam ainda outras que alteram o próprio espaço social da infância." (FERREIRA, 2004, p. 78).

Ao brincar, a criança traz consigo possibilidades de mudança, de ressignificação, de criar um mundo próprio, de libertar-se, de colocar-se em outro lugar, de fazer sempre de novo, de virar ao contrário...

\section{(Des)Objetos do brincar... Seus usos e sentidos atribuídos pelas crianças}

No espaço pesquisado, observaram-se inúmeras relações entre as crianças e os "objetos do brincar". Destaca-se a partir de suas falas e ações sua capacidade de atribuir outros sentidos e valores aos objetos com seus pares.

Marco Antônio (4 anos e 10 meses) ao chegar à brinquedoteca corre para o espaço onde se localiza o "supermercado". Pega uma embalagem de margarina e a manipula por um tempo. Abre e fecha a tampa, olha para as letras e cores que a compõem, cheira... Após um tempo de manipulação, retira uma tampa de refrigerante de outra embalagem e a coloca dentro da embalagem de margarina. Balança de um lado para o outro, sacode, parece estar apreciando o som que a tampa de refrigerante provoca ao balançar na embalagem de margarina. Pedro (4 anos e 6 meses) aproxima-se e pergunta: O que tem aí dentro, Marco? Isso é um bicho? Marco sorri, responde que sim, sacode a embalagem e sai correndo atrás de Pedro, que corre 
simulando estar com muito medo. Os dois correm, Pedro se esconde, Marco Antônio o encontra e a brincadeira segue com trocas de olhares e sorrisos de contentamento entre eles. Após um tempo brincando, os dois meninos se sentam dizendo estarem cansados. Marco Antônio olha para a lata de margarina ainda em suas mãos, lança um olhar na direção de Pedro e fala: A brinquedoteca é legal, né? A gente tem um monte de brinquedos... Lá em casa, não tem brinquedo, só tem videogame... (Diário Campo).

A cena demonstra a capacidade de produção simbólica das crianças e os diferentes sentidos que atribuem ao mundo que as cerca. A brincadeira de "assustar" criada a partir de uma simples embalagem de margarina e tampa de refrigerante evidencia que os objetos comunicam, expressam e veiculam conteúdos. Porém, a criança olha além da materialidade dos objetos e atribui outras significações simbólicas.

Marco Antônio, ao explorar e brincar com as sucatas encanta-se e explicita: "lá em casa não tem brinquedo, só tem videogame”. Embalagem de margarina se transforma em brinquedo precioso. Videogame passa a ter um valor menor. O menino modifica a lógica, valora objetos que, aos olhos dos adultos, podem não ter valor algum. Olhar invertido, outros pesos e medidas... Tal como nos aponta a criança em Benjamin (1986):

as crianças se sentem irresistivelmente atraídas pelos destroços que surgem da construção, do trabalho no jardim ou em casa, da atividade do alfaiate ou do marcineiro. Nestes restos que sobram, elas reconhecem o rosto e o mundo das coisas que se voltam exatamente para elas, e só para elas. Nestes restos elas estão menos empenhadas em imitar as obras dos adultos do que em estabelecer entre os mais diferentes materiais, através daquilo que criam em suas brincadeiras, uma nova e incoerente relação. Com isso, as crianças formam o seu próprio mundo das coisas, mundo pequeno inserido em um maior. (BENJAMIN, 1986, p. 77).

O autor, ao rememorar sua própria infância, aponta-nos a capacidade de encantamento das crianças. Diante de coisas, muitas vezes, miúdas, elas estabelecem outras relações com a materialidade dos objetos e criam seu próprio mundo, quando o ressignifica. Segundo o mesmo autor, as crianças brincam nos canteiros de obra com os detritos da humanidade. Por enxergarem grandeza nas coisas simples, voltam seus olhos para o chão, brincam com aquilo, que não é, em princípio, brinquedo. Aquilo que aos olhos dos adultos não tem valor, para elas pode ser a revelação de uma brincadeira.

$\mathrm{O}$ contexto material, temporal e relacional da brinquedoteca permitia à criança observar, manipular, descobrir, encontrar e brincar junto de outras crianças. Embora o espaço, conforme apresentou-se anteriormente, fosse composto por áreas temáticas que configuravam e comunicavam possíveis itinerários de brincadeiras, as crianças vão além, transveem e criam enredos únicos e inimagináveis. 
Valorizar o que é desvalorizado. Embalagens abandonadas, aparentemente lixo, podem se tornar poesia... Ao brincar, as crianças se comportam como poetas, que reajustam os elementos do mundo, atribuindo-lhes outros sentidos e significados.

\section{O brincar da criança como um elemento que ressignifica e transforma a organização do espaço proposto pelo adulto}

A partir de suas formas específicas de conhecer e de se relacionar com o mundo e no mundo, as crianças transformam espaços, objetos e brinquedos em novas elaborações. Não é o conteúdo imaginário do brinquedo que determina a brincadeira, mas é a criança que determina esse conteúdo (BENJAMIM, 2005). Na brinquedoteca, observou-se o compartilhamento de sentidos entre crianças, que foi respeitado, acolhido pelos adultos e implicou em uma nova configuração do espaço. Tal como na cena abaixo:

Um novo brinquedo chega à brinquedoteca. Confeccionado pela brinquedista e pela estágiária é denominado por elas como "Túnel do tempo". Trata-se de uma caixa de fogão grande, pintado por dentro e por fora com a cor preta. Na caixa há uma abertura para as crianças entrarem. No interior da caixa, há um monitor e um teclado de computador. O "Túnel do tempo" foi disposto no canto temático das tocas e cabanas. Como toda novidade, o brinquedo causou curiosidade entre as crianças. Carolina (4 anos), André (4 anos e 6 meses) e Lucas (3 anos e 7 meses), ao chegarem à brinquedoteca, olharam para caixa admirando-a. André pergunta à brinquedista: O que é isso? A brinquedista explica: Esse brinquedo é um túnel do tempo. Nele podemos viajar no tempo e no espaço, podemos ser quem quisermos! André olha novamente para o brinquedo, olha para os colegas e fala: Ai! gente eu sei, isso é a casa monstro!!! Carolina fala: Eu quero, eu quero entrar na casa monstro. As três crianças entram e ficam no interior da caixa, simulando que estão assustadas. A brinquedista acompanha o movimento das crianças, rapidamente retira do armário um pacote de morcegos de plástico e convida as crianças para pendura-los no interior da "casa". As crianças aceitam o convite entusiasmadas. Logo que terminam de pendurar os morcegos, Carolina fala: Tia, agora só falta o fantasma e o monstro.... A brinquedista responde: Puxa, é mesmo! E agora, como vocês acham que podemos fazê-los? As crianças vão sugerindo, enquanto ela pega alguns materiais como tesoura, caixas, papéis, cola para ornamentar a, agora,“Casa Monstro”. (Diário de campo).

A confecção de um novo brinquedo pela brinquedista revela cuidado e preocupação com a ampliação e oferta de materiais para as crianças. O espaço do brincar é pensado, planejado. No entanto, o objeto previamente concebido pelo adulto apresenta características que remetem a uma lógica adultocêntrica. A confecção de um brinquedo como o "túnel do tempo" parece não emergir das necessidades infantis. Transver os limites do tempo e do espaço é algo que as crianças já realizam, sem precisar de um brinquedo específico para isso. Através das expressões "faz de conta 
que..." ou do "novamente, outra vez..." elas transgridem, ultrapassam os limites do tempo e do espaço. Por meio da imaginação e da repetição, a criança “instala um "de novo" que é prenúncio de uma trajetória que não cessa". (BENJAMIN 2005, p. 2).

Conforme mencionou-se anteriormente, a brinquedoteca, assim como outros espaço coletivos da infância, é concebida pelos adultos para uso das crianças, por isso contém uma visão adulta sobre o que seriam as necessidades e desejos das crianças (LIMA 1981). Portanto, antes de ser um espaço $d a$ criança, é um espaço pensado para ela. Esse fato provoca inquietações quanto à sua organização: Será que, quanto mais o espaço for elaborado, pensado e planejado pelos adultos, menos possibilidades ele terá de se constituir em um espaço da criança? De acordo com Lima ( 1981):

É preciso, pois, deixar o espaço suficientemente pensado para estimular a curiosidade e a imaginação da criança, mas incompleto o bastante para que ela se aproprie e transforme esse espaço através de sua própria ação. (LIMA, 1989, p. 72).

Organizar espaços que promovam a curiosidade, a imaginação e a descoberta é uma forma de reconhecer o direito das crianças de brincar e de viver sua infância em plenitude não apenas na escola. No entanto, é preciso compreender que esses lugares precisam ser construídos e reconstruídos permanentemente pelos sujeitos que os habitam. Os espaços da infância precisam considerar os diferentes modos de organização das crianças.

$\mathrm{Na}$ pesquisa, a brinquedista, ao acompanhar o movimento das crianças e acolher suas manifestações, possibilita que elas também imprimam marcas e reorganizem o espaço a elas destinados. Por meio de relações embasadas na troca, no compartilhamento e no respeito, a brinquedoteca deixou de ser apenas um espaço para as crianças. Quando o espaço foi pensado com elas, constituiu-se em um espaço das crianças.

Para que os espaços da infância possam se constituir em lugares das crianças, é necessário que seja possibilitado a elas deixar marcas, expressar suas opiniões, ideias e desejos participando efetivamente de sua organização.

\section{Brincadeiras, narrativas... ou sobre o que acontece quando adultos e crianças se encontram}

Nas relações, nos encontros e nas brincadeiras, efetiva-se a produção de sentidos. Tal processo implica-se pensar crianças e adultos convivendo juntos. Percebeu-se, na pesquisa, o quanto a presença do adulto brinquedista perpassa os espaços do brincar da criança. Na criação de contextos materiais, temporais e sociais, a presença do adulto permite, proíbe, incentiva e sustenta (ou não) as vivências, as significações. 
Ao sustentar contextos e participar de suas brincadeiras, os adultos possibilitam o estabelecimento de trocas sociais, a criação de vínculos afetivos, o sentido de pertencimento e, sobretudo, o encontro com as narrativas. Como exemplo, cita-se a seguinte cena:

Gabriela (4 anos e 2 meses), Nicole ( 4 anos), Luiza ( 3 anos e 10 meses), João (3 anos e 6 meses) e Larissa (4 anos e 2 meses) estão sentados em roda brincando de a "galinha quer pôr". A brinquedista aproxima-se e Gabriela, ao perceber sua presença, fala: Tia, tu quer brincar com a gente? A brinquedista responde: Oba! Quero sim. Após brincarem por algum tempo dessa brincadeira, a brinquedista diz conhecer uma outra brincadeira de roda: a "viuvinha". Fala às crianças: Quando eu era pequena, do tamanho de vocês, essa era minha brincadeira preferida. As crianças sorriem, trocam olhares entre si. A brinquedista explica as regras e as convida para brincar. As crianças sorrindo, prontamente, aceitam o convite. A brinquedista começa a cantarolar a cantiga "Viuvinha, por que choras? Sentes falta de um carinho se levante e abrace eu. Mas quem sou eu?" A criança que representa a viuvinha fica ao centro da roda. Ao final da cantiga, levanta e abraça um colega. A cantiga e o envolvimento das crianças fez com que outras crianças se interessassem pela brincadeira. Aos poucos, praticamente todo o grupo participa da brincadeira. Ao final da cantiga, ouvia-se um "de novo" e a brincadeira continuava. Após um período repetindo a brincadeira, as crianças, pouco a pouco, vão se dispersando. A brinquedista é chamada na porta e sai para atender uma pessoa que pede informações. Restam na roda apenas Gabriela, Nicole e Luiza. As meninas desejam continuar a brincadeira, mas percebem que o número de participantes é limitado. Logo Gabriela fala: Tive uma ideia, vamos convidar as bonecas para brincar com a gente? Nicole pega uma boneca e Luiza outra. Seguram-nas pelos braços e fazem uma roda intercalando bonecas e meninas. Gabriela fica ao centro da roda representando a viuvinha. Logo, a cantiga inicia e a brincadeira recomeça. (Registro em vídeo)

Ao aceitar o convite de Gabriela para brincar, a brinquedista supõe a existência de uma criança que é ativa, comunicativa, potente, capaz de iniciar e manter brincadeiras. Após brincar por um longo período de "galinha quer pôr" a brinquedista sugere brincar de "viuvinha". Ela narra a brincadeira e compartilha com as crianças uma outra forma de brincar de roda e relata: "Quando eu era pequena, essa era minha brincadeira preferida!". O repertório de brincadeira das crianças é ampliado. E essa brincadeira passa a ser bastante partilhada. Em alguns momentos, era iniciada pela brinquedista, em outros, como na cena anterior, pelas crianças, que quando não encontram números suficientes de participantes, criam alternativas e diferentes formas de brincar.

Brougère (2012) em entrevista a Barbara Rogoff, destaca a importância da participação das crianças nos processos educativos no cotidiano. Para o autor aprendizagem e participação são elementos indissociáveis. "Se aprende sem necessariamente se dar conta disso, sem nem sempre 
querer. O que importa é participar, fazer com outros, ser membro de uma comunidade. (...) Aprender é participar e participar é aprender.” (BROUGÈRE, 2012, p. 313-314).

Adultos e crianças participantes, aprendizes. No compartilhamento de signos, sentidos, significados, experiências são tecidas entre as lembranças de adultos que brincaram, e ao mesmo tempo, entre novas formas de brincar ressignificadas na relação com crianças.

Para Benjamin (1986), a origem da narrativa é a experiência humana. É sobre ela que o narrador transforma a sua própria experiência em algo útil para os outros. A brincadeira fazia parte da experiência da brinquedista e era narrada por ela, no cotidiano, para o outro.

Kishimoto (1998) aponta que, atualmente, a falta de espaços públicos que valorizem o encontro entre diferentes gerações impossibilita a transmissão oral e o encontro com narrativas. Segundo a autora, as narrativas perdem-se, guardadas em gavetas que não foram mais abertas. Aspecto esse, já sinalizado por Benjamin (2005):

Contar histórias sempre foi a arte de contá-las de novo, e ela se perde quando as histórias não são mais conservadas. Ela se perde porque ninguém mais fia ou tece enquanto ouve a história. Quanto mais o ouvinte se esquece de si mesmo, mais profundamente se grava nele o que é ouvido. Quando o ritmo do trabalho se apodera dele, ele escuta as histórias de tal maneira que adquire espontaneamente o dom de narrá-las. Assim se teceu a rede em que está guardado o dom narrativo. E assim essa rede se desfaz hoje por todos os lados, depois de ter sido tecida, há milênios, em torno das mais antigas formas de trabalho manual. (BENJAMIN, 2005 p. 205).

Para que o passado não se perca, é preciso narrar no sentido benjaminiano, intercambiar experiências. $\mathrm{Na}$ organização de tempos e espaços para o estabelecimento de um diálogo entre gerações, novos sentidos se constroem e diferentes perspectivas se anunciam...

Sendo a brinquedoteca considerada um espaço de "veiculação da cultura infantil, da integração social e da construção de representações infantis" (KISHIMOTO, 1997, p. 35), acreditase que precisa configurar-se em um espaço significativo, capaz de potencializar encontros, narrativas e produção de sentidos e saberes. A criança vive sua infância na materialidade do espaço, por isso, considera-se fundamental que ele seja rico, diverso em materiais e brinquedos. O espaço é potente. Mas, é o olhar, o toque, as relações, as brincadeiras, as narrativas que possibilitam à criança, produzir saberes, sentidos e significar os espaços em que vivem.

\section{CONSIDERAÇÕES FINAIS PARA ESSE TEMPO DE ESTUDO}

Frente à importância do brincar para a constituição do sujeito e da falta de espaços educativos não formais promotores de brincadeiras coletivas na sociedade contemporânea, buscou- 
se olhar para a brinquedoteca, local especificamente organizado para o brincar e focar a capacidade de produção simbólica das crianças.

No diálogo com diferentes autores, afirma-se a importância do espaço que potencializa ou limita a brincadeira das crianças. As crianças têm direito a espaços de qualidade para brincar. Ao olhar para as configurações físicas da brinquedoteca, no presente trabalho, percebeu-se que esse espaço, organizado inicialmente pelos adultos, propõe fisicamente itinerários de brincadeiras. Os objetos concretos que compõem os cantos temáticos, pelo seu poder expressivo, comunicam mensagens e expressam ideias.

Diante do espaço, as crianças vão além, transveem materialidades. Na sutileza dos olhares, nos encontros, nas brincadeiras, na riqueza de narrativas as crianças apropriam-se dos espaços, criam diferentes enredos, produzem outros sentidos e saberes evidenciando, por meio de suas manifestações, a sua capacidade de produção simbólica.

No decorrer da pesquisa, percebeu-se que o contexto material, temporal e relacional da brinquedoteca permitia a criança observar, manipular, descobrir, encontrar e brincar com seus pares. Os saberes e sentidos compartilhados entre elas, foram respeitados e acolhidos pelos adultos, implicando, em novas formas de organização e configuração do espaço.

Brincadeiras, narrativas. Na relação com os adultos, a criança constrói saberes, atribuí sentidos e significados. Ao ler histórias, cantar músicas, participar de brincadeiras o adulto possibilita a criança o encontro com narrativas. Observou-se no contexto pesquisado, que por meio de narrativas advindas da memória de adultos que brincaram, houve compartilhamento de saberes e sentidos, significados entre crianças e adultos. No encontro entre gerações emergiram novas possibilidades de brincar.

Compreender a criança como sujeito ativo, competente nas relações, capaz de falar de si e dos outros, requer organizar espaços educativos não formais para a infância em uma perspectiva, que considere os sentidos e saberes produzidos por elas. Pensar espaços/tempos atentos ao delicado e sutil processo de constituir-se sujeito por meio do brincar.

O melhor da brincadeira foi imaginar, criar, ressignificar. Objetos exerceram diferentes papéis e funções. Embalagens abandonadas transformaram-se em brinquedos preciosos. Espaços se transmutaram em infinitos cenários. De túnel do tempo à casa monstro. Liberdade e criatividade moldando um brincar que multiplica possibilidades, enriquecendo saberes e viveres... 


\section{REFERÊNCIAS}

AGOStinhO, K. A. O espaço da creche: que lugar é esse? 2003. Dissertação (Mestrado)-Universidade Federal de Santa Catarina, Florianópolis, 2003.

ANDRÉ, M.E.D.A. A etnografia na prática escolar. 5. ed. Campinas, SP: Papirus. 2000.

BARBOSA, S.N.F. Nas tramas do cotidiano: adultos e crianças construindo a educação infantil. Dissertação (Mestrado em Educação) - PUC-Rio, Rio de Janeiro, 2004.

BENJAMIN, W. Magia e técnica, arte e política. 2. ed. São Paulo: Brasiliense, 1986.

. Reflexões: a criança, o brinquedo e a educação. São Paulo: Duas Cidades, 2005.

BROUGÈre, G. Aprender pela vida cotidiana. Campinas: Autores associados, 2012.

CERTEAU, M. de. A invenção do cotidiano: 1. artes de fazer. Petrópolis: Vozes, 1994.

FERREIRA, M. M. A gente gosta é de brincar com os outros meninos!: relações sociais entre crianças num Jardim de Infância. Porto, Portugal: Edições Afrontamento, 2004.

GOHN, M. G. Educação não-formal, participação da sociedade civil e estruturas colegiadas nas escolas. Ensaio, Rio de Janeiro, v.14, n. 50, p. 27-38, jan./mar. 2006.

JOBIM E SOUZA, S. Ressignificando a Psicologia do desenvolvimento; uma contribuição crítica a pesquisa da infância. In: KRAMER, S.; LEITE, M.I. (Orgs.). Infância: fios e desafios da pesquisa. Campinas: Papirus, 1996. p. 39-55.

KISHIMOTO, T. M. Brinquedo e brincadeira uso e significações dentro de contextos culturais. In: SANTA, M.P.S. (Org.). A brinquedoteca: o lúdico em diferentes contextos. Petrópolis: Vozes, 1997. p. 23-40.

Diferentes tipos de brinquedoteca. In: FRIEDMANN, A. O direito de brincar: a brinquedoteca. 4. ed. São Paulo: Abrinq, 1998. p. 53-63.

Brinquedos e materiais pedagógicos nas escolas infantis. In: Educação e Pesquisa. Revista da Faculdade de Educação da USP, São Paulo, v. 27, n. 2, p. 229-265, jul.-dez. 2001.

KRAMER, S. Infância, cultura e educação. In: PAIVA, A.; EVANGELISTA, A.; PAULINO, G.; VERSIANI, C. (Orgs.). No fim do século: a diversidade - o jogo do livro infantil e juvenil. Belo Horizonte: Autêntica, 2000. p. 9-34.

LIMA, M. S. A cidade e a criança. São Paulo: Nobel Livraria, 1981.

PETERS, L.L. Brincar para quê? Escola é lugar de aprender! estudo de caso de uma brinquedoteca no contexto escolar. 2009. Tese (Doutorado em Educação) - Programa de Pós-Graduação em Educação-Universidade Federal de Santa Catarina, Florianópolis, 2004.

PINTO, M.; SARMENTO, M. J. As crianças, contextos e identidades. Portugal, Centro de Estudos da Criança: Editora Bezerra, 1997.

PORTO, C.L. Brinquedo e brincadeira na brinquedoteca. In: KRAMER, Sonia; LEITE, Maria Isabel. Infância e produção cultural. São Paulo: Papirus, 2005. p. 171-198.

SANTOS, M. A natureza do espaço: técnica e tempo, razão e emoção. 4. ed. São Paulo: Edusp, 2002.

TUAN, Y. Espaço e lugar: a perspectiva da experiência. São Paulo: Difel, 1983.

VIÑAO FRAGO, A.; ESCOLANO, A. Currículo, espaço e subjetividade: a arquitetura como programa. Rio de Janeiro: DP\&A, 1998.

ZANELLA, A.V. Atividade, significação e costituição do sujeito: considerações à luz da psicologia histórico-cultural. In: Revista Psicologia em estudo. Maringá, vol. 9, n. 1, p. 127-135, 2004. 


\section{RESUMO}

O texto tem por foco evidenciar os modos como as crianças ocupam, se relacionam, produzem sentidos no espaço da brinquedoteca. Defende-se que sendo a brinquedoteca um espaço estruturado para o brincar, sua materialidade educa e comunica mensagens. Porém, essas não são imutáveis. A partir da ocupação e das interações que as crianças estabelecem entre si e com adultos, sentidos são produzidos e outras significações simbólicas são atribuídas ao espaço. Os resultados desvelam indicadores que pretendem contribuir para (re)pensar os espaços coletivos da infância, evidenciando a participação da criança como sujeito ativo, competente, produtor de saberes capaz de falar de si e dos outros por meio do brincar.

Palavras-chave: criança; produção de sentido; espaço; brinquedoteca.

\section{THE SPACE OF PLAYROOM AND THE PRODUCTION SENSES AMONG CHILDREN}

\section{ABSTRACT}

This text has the focus highlight the ways in which children occupy, relate, produce meanings and knowledge within the playroom. We argue that the playroom is a structured space for play, its materiality educates and communicate messages. But these are not immutable. From the occupation and interactions that children establish among themselves and with adults, meaning they are produced and other symbolic meanings are attributed to space. The results unveil indicators that aim to contribute to spaces and children, showing the child's participation as an active subject, competent, knowledge producer able to talk about themselves and others through play.

Keywords: child; production of meaning; space; playroom.

Submetido em: Out. 2016 Aprovado em: Fev. 2017 